\title{
7. DRILL SITE SURVEYS, LEG 37
}

\author{
R.J. Iuliucci and F. Aumento, Department of Geology, Dalhousie University, Halifax, Nova Scotia, Canada
}

In January 1974, the CSS Hudson surveyed in detail a small area on the west flank of the Mid-Atlantic Ridge near $37^{\circ} \mathrm{N}$ in preparation for the deep-penetration drilling attempts to be made later that year during Leg 37 of the Deep Sea Drilling Project. During Leg 37, in June and July 1974, Glomar Challenger collected an additional $500 \mathrm{~km}$ of underway data around and between the leg's four drill sites.

Data collected on these cruises included precision depth recordings at $12 \mathrm{kHz}$, earth's total field magnetometer measurements, and continuous seismic reflection profiles using two simultaneous airgun sound sources. Navigation of both ships was by satellite; in addition, the tight-grid Hudson survey of the valley in which Sites 332 and 333 were located, hereafter referred to as the Deep Drill Valley, was further controlled by two moored radar transponder buoys.

Figure 1 shows the Glomar Challenger's track in the area bounded by latitudes $36^{\circ}$ and $38^{\circ} \mathrm{N}$, and longitudes $32^{\circ} 30^{\prime}$ and $36^{\circ} \mathrm{W}$. The inset, upper left, locates this area regionally, and the inset, upper right, gives the detail of the track between Sites 332 and 333 . A track chart showing the Glomar Challenger's track to and from this area appears in Iuliucci et al., this volume.

The underway geophysical data presented (Figures 24) consist of photographic reproductions of original seismic reflection records collected during Leg 37, with the corresponding magnetic anomaly profiles. The horizontal scale is GMT time, the vertical scale is travel time in seconds for the seismic profiles, and gammas for the magnetic profiles. Magnetic anomalies were extracted from total field measurements following the visual fitting of a linear regional magnetic gradient over the segments in question. Vertical exaggeration for the reflection profiles is approximately 70 to 1 , at 18.5 $\mathrm{km} / \mathrm{hr}$ (10 knots), but varies with ship's speed. The track segments are labeled with "Line" numbers in Figures 1 through 4 to facilitate discussion. Line 1 is the track into the first drill site, Lines $2-4$ are the tracks between sites, and Line 5 is the track out of the area. The normal polarity magnetic intervals are labeled by number.

Figure 5, which shows the bathymetry of Deep Drill Valley, was taken from data collected by the Hudson cruise, 74-003. Cross-sections A-A', and B-B' show profiles along the tracks closest to Sites 332 and 333, respectively.

The Leg 37 drill sites were chosen to sample and investigate possible secular variations in basalt sequences of Median Valley origin. Consequently, they were located along a transect parallel to the direction of spreading, bearing $285^{\circ}$, the line chosen so that it would pass through the Mid-Atlantic Ridge median valley site of the FAMOUS dives. The bulk of Glomar Challenger underway data presented was collected over the $150-\mathrm{km}$ interval between Deep Drill Valley, located some $30 \mathrm{~km}$ west of the Median Valley, and Site 335, $180 \mathrm{~km}$ out (Figure 1).

This $150 \mathrm{~km}$ is located on a portion of the American plate generated between approximately $3.5 \mathrm{~m} . \mathrm{y}$. (Sites 332 and 333 ), and 13 m.y. ago (Site 335). This relatively young section of plate exhibits abundant evidence of spreading activity. The area is one of intense fracturing, both by block faults parallel to the spreading axis and transverse to it along fracture zones: it has well-defined magnetic anomalies associated with the faulting, and exhibits decreasing sediment thickness as well as water depth as the ridge axis is approached (Figures 2-4).

Line 1 (Figures 1 and 2) shows the Glomar Challenger's track approaching Site 332 after 11 days transit from Recife, Brazil. Coverage begins $(2315 \mathrm{hr}$, 16 June 1974) as the Challenger was transiting obliquely across the western flank of the Mid-Atlantic Ridge to a point WNW of Deep Drill Valley. The track then follows the Leg 37 transect line, past the location later selected to drill Site 334 ( $0835 \mathrm{hr}, 17$ June 1974$)$, to the first of many crossings of Deep Drill Valley (1225-1235 $\mathrm{hr}$ ), and terminates at Site 332 . The sweep speed of the seismic recorder was changed to $2 \mathrm{sec}$ from $5 \mathrm{sec}$ (1340 $\mathrm{hr}$ ) in an attempt to improve record resolution.

Line 2 covers a small area within $10 \mathrm{~km}$ of the axis of Deep Drill Valley, and includes five crossings of the valley. Deep Drill Valley is one of a series of elongate hills and troughs trending $015^{\circ}$, paralleling the MidAtlantic Ridge axis. Where Sites 332 and 333 were drilled (Figure 3, Line 2; Figure 5) the sedimentcovered valley floor is about $2.5 \mathrm{~km}$ wide and deepens northward with a 1:50 gradient. The eastern wall of the valley rises 150 meters above the floor, the western wall 250 meters. The surrounding ridges are asymmetric with steeper sides facing east (scarp slopes).

The sediment blanketing the valley floor is a maximum 0.35 sec thick (two-way acoustic travel time) and is acoustically transparent with little internal layering evident. The sediment was found by drilling to be predominantly a foram-bearing nannofossil ooze with a sonic velocity (measured onboard Glomar Challenger) of $1.59 \mathrm{~km} / \mathrm{sec}$, indicating there is a maximum sediment thickness in the order of 275 meters. The marked erosional channels along this and adjacent valleys' margins, and the absence of sediment on the ridges, clearly indicate that the entire area is being scoured by bottom currents.

Line 3 (Figure 3), the track from Site 333 to 334, repeats in reverse a previously transited section, but Line 4 (Figure 3) en route to Site 335, is a deeper excursion onto the American plate and into the depths of the 


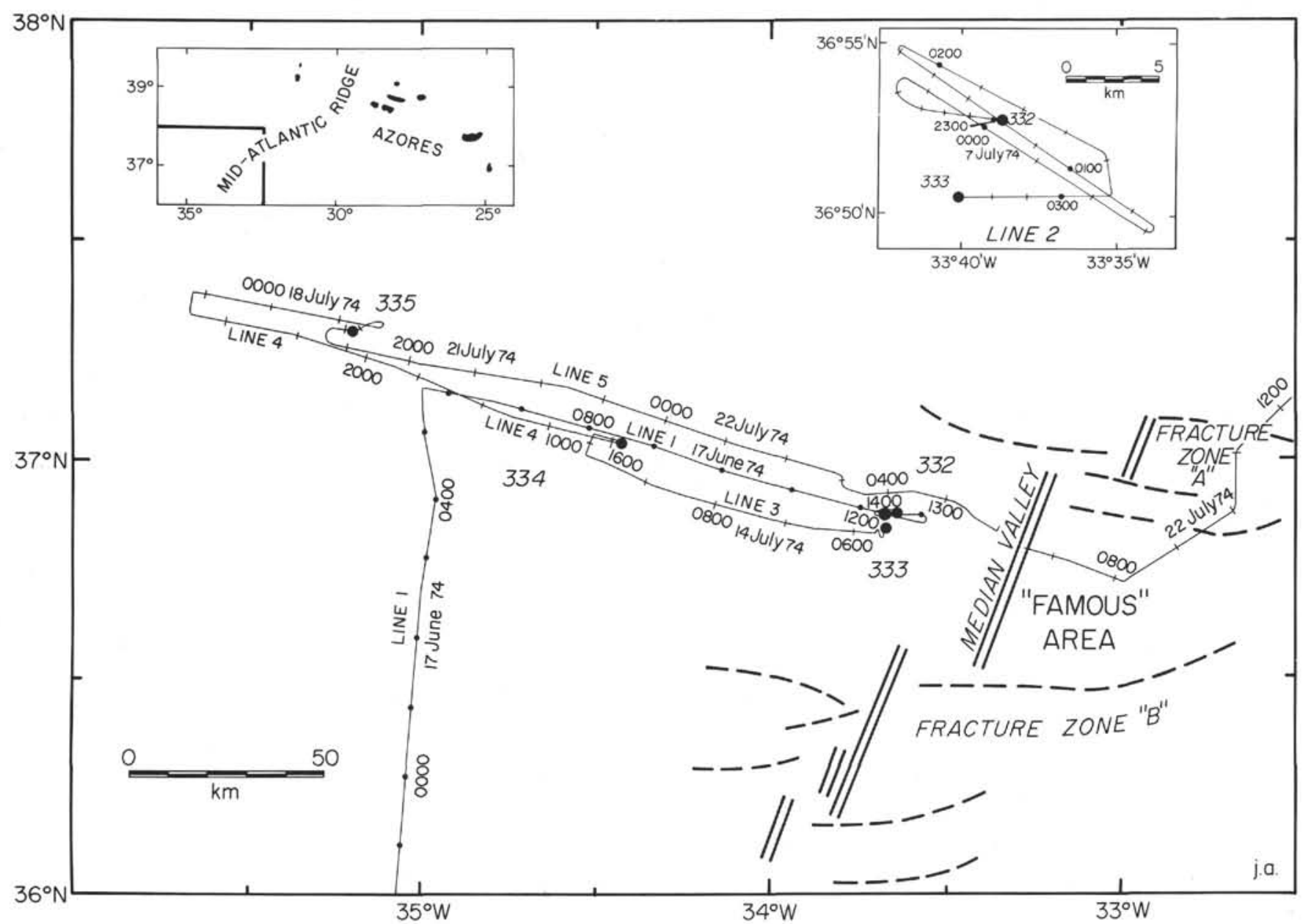

Figure 1. Track chart of Glomar Challenger in the vicinity of Leg 37 drill sites. Track is annotated in GMT hour and date and by line number. Inset, upper left, locates this area regionally, Inset, upper right, annotated every 10 minutes, gives the detail of the track between Sites 332 and 333.

ocean basin. Along this line sediment cover thickens, and now is not restricted only to ponds between basement highs, but entirely covers broad areas of crustal highs and lows. During this run, for the first time in the records presented, the sediment column contains an internal seismic reflecting horizon $(2000 \mathrm{hr}, 17$ July onward) which resolves into a discrete layer by the time Site 335 is reached (0100-0200 hr, 18 July). At Site 335 this reflector is $0.13 \mathrm{sec}$ subbottom, which places the layer approximately 105 meters subbottom. A drill core was not taken at this level but cores from above and below, at 87 meters and 125 meters, contained sedimentologically identical foram-bearing nannofossil ooze. Pumice fragments were noted at Sites 332 and 333 in late Pliocene ooze of an estimated 2.3-3.0 m.y. age, a time interval that was not cored at Site 334. At Site 335 the cores above and below this seismic reflector bracket the interval between 2.0 and $3.5 \mathrm{~m}$.y. so the reflector horizon quite probably is a thin ash layer.

Line 5 (Figure 4) is the Challenger's track out of the Leg 37 drilling area towards the port of Dublin, Ireland. The ship crossed the Mid-Atlantic Ridge crest (0630 hr, 22 July 1974) in an area where a transverse fault obscures the Median Valley. Once onto the African plate the ship turned to the northeast, and entered the fracturing associated with Fracture Zone " $A$ " $(0930 \mathrm{hr})$ where coverage ends. 

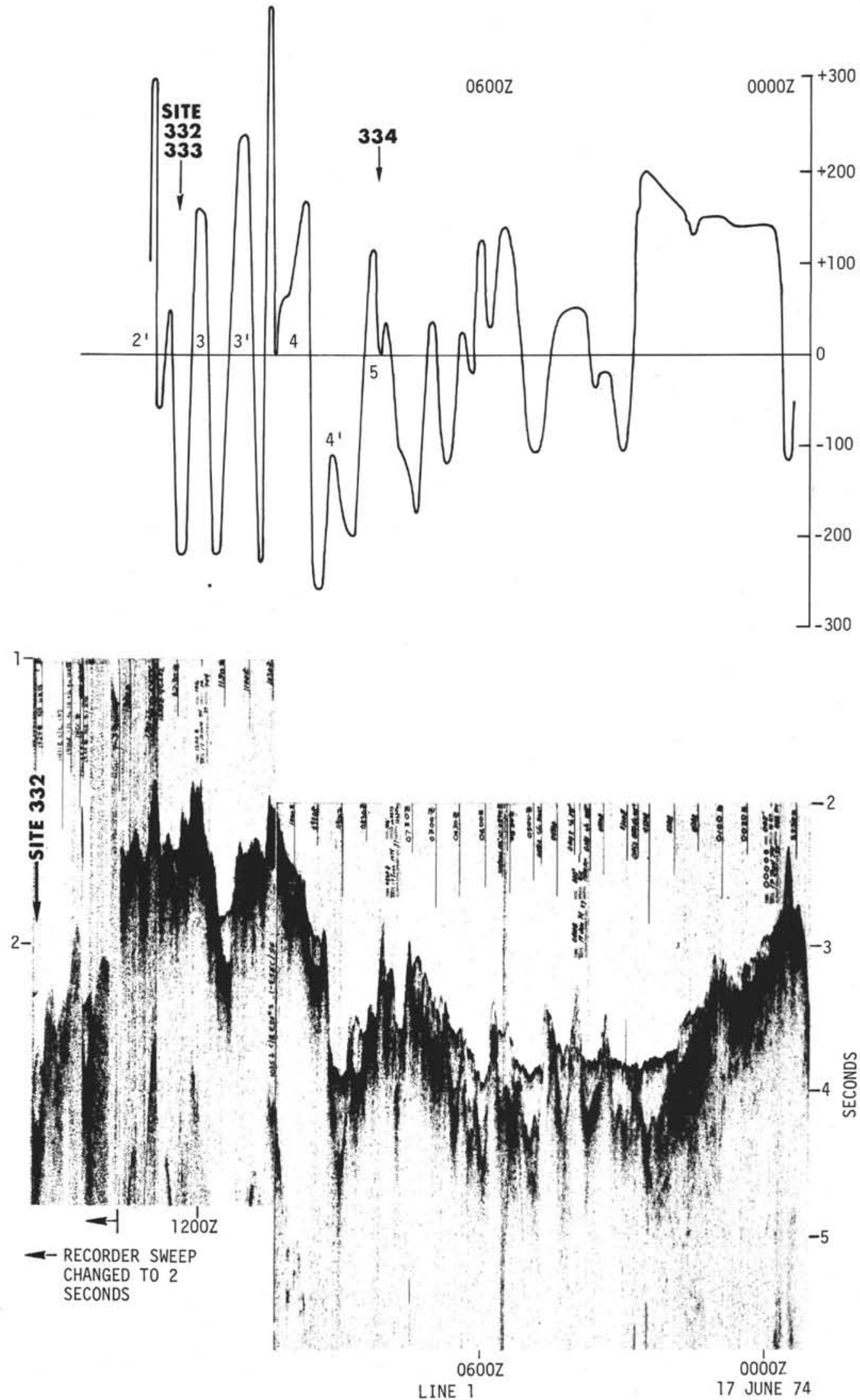

Figure 2. Glomar Challenger, Leg 37, seismic reflection and magnetic anomaly profiles for Line 1, the track into Site 332. 


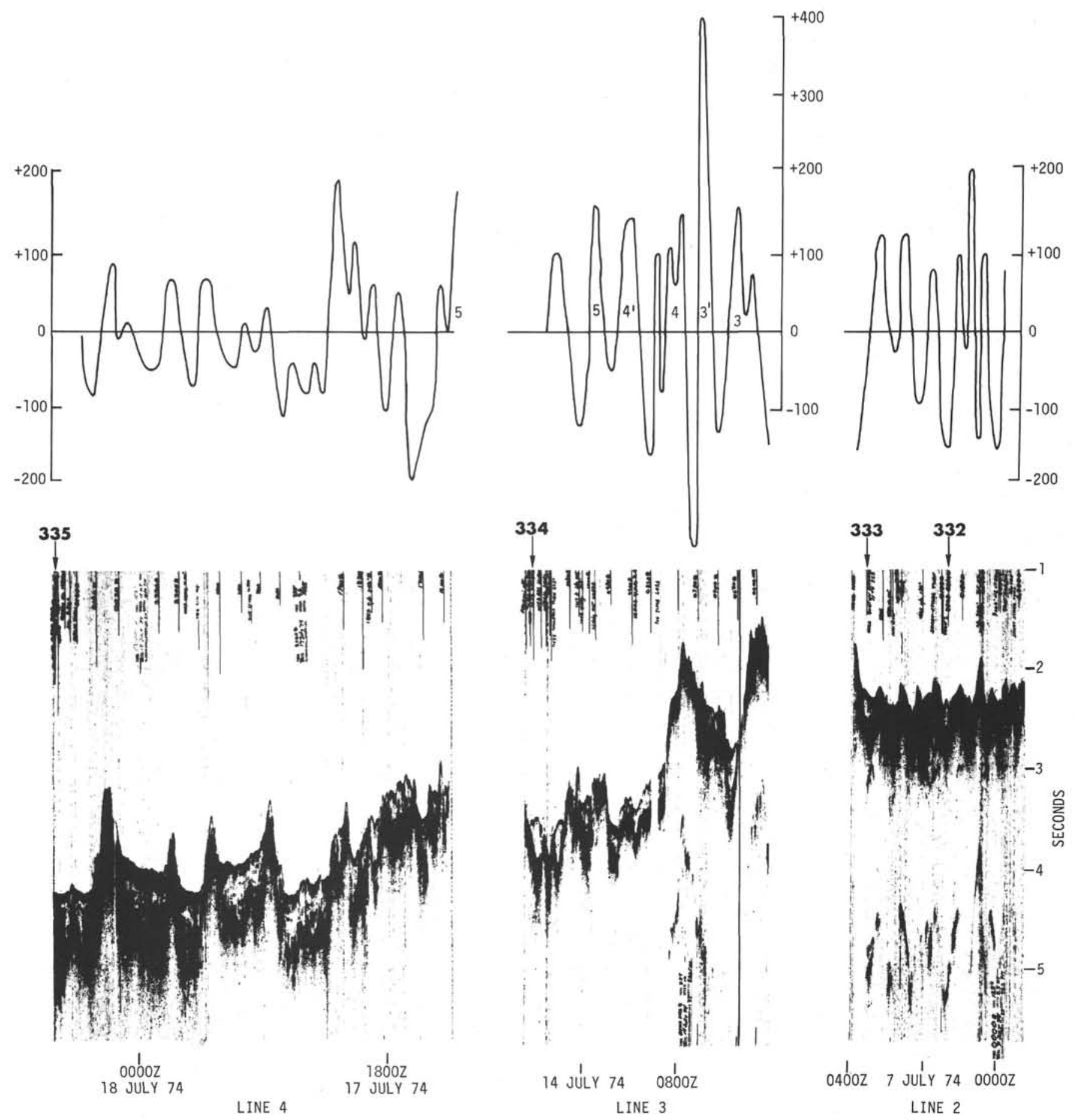

Figure 3. Glomar Challenger, Leg 37, seismic reflection and magnetic anomaly profiles for Lines 2, 3, 4 with the locations of Sites 332, 333, 334, and 335 indicated. 

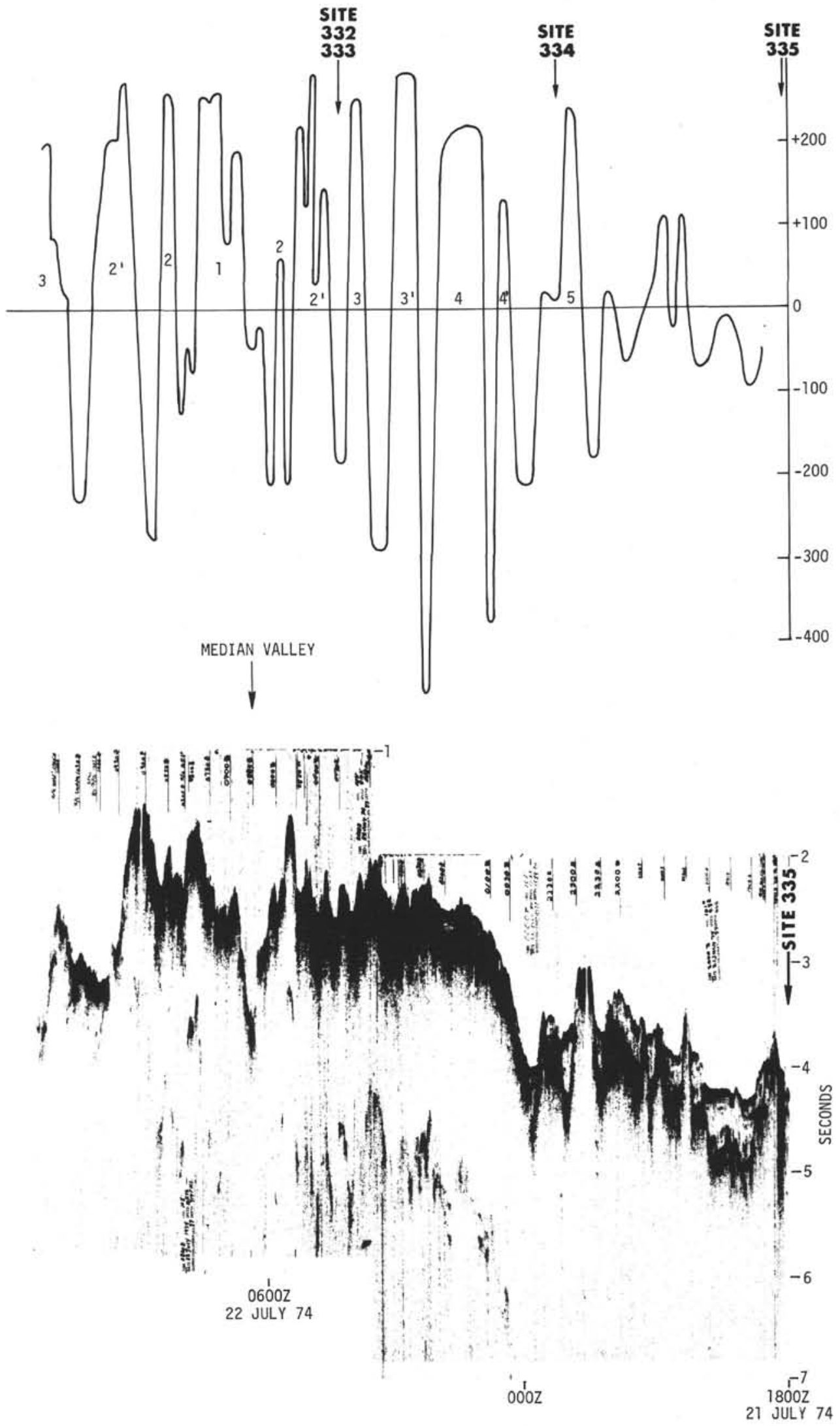

Figure 4. Glomar Challenger, Leg 37, seismic reflection and magnetic anomaly profiles for Line 5 , the track out of the drilling area. 

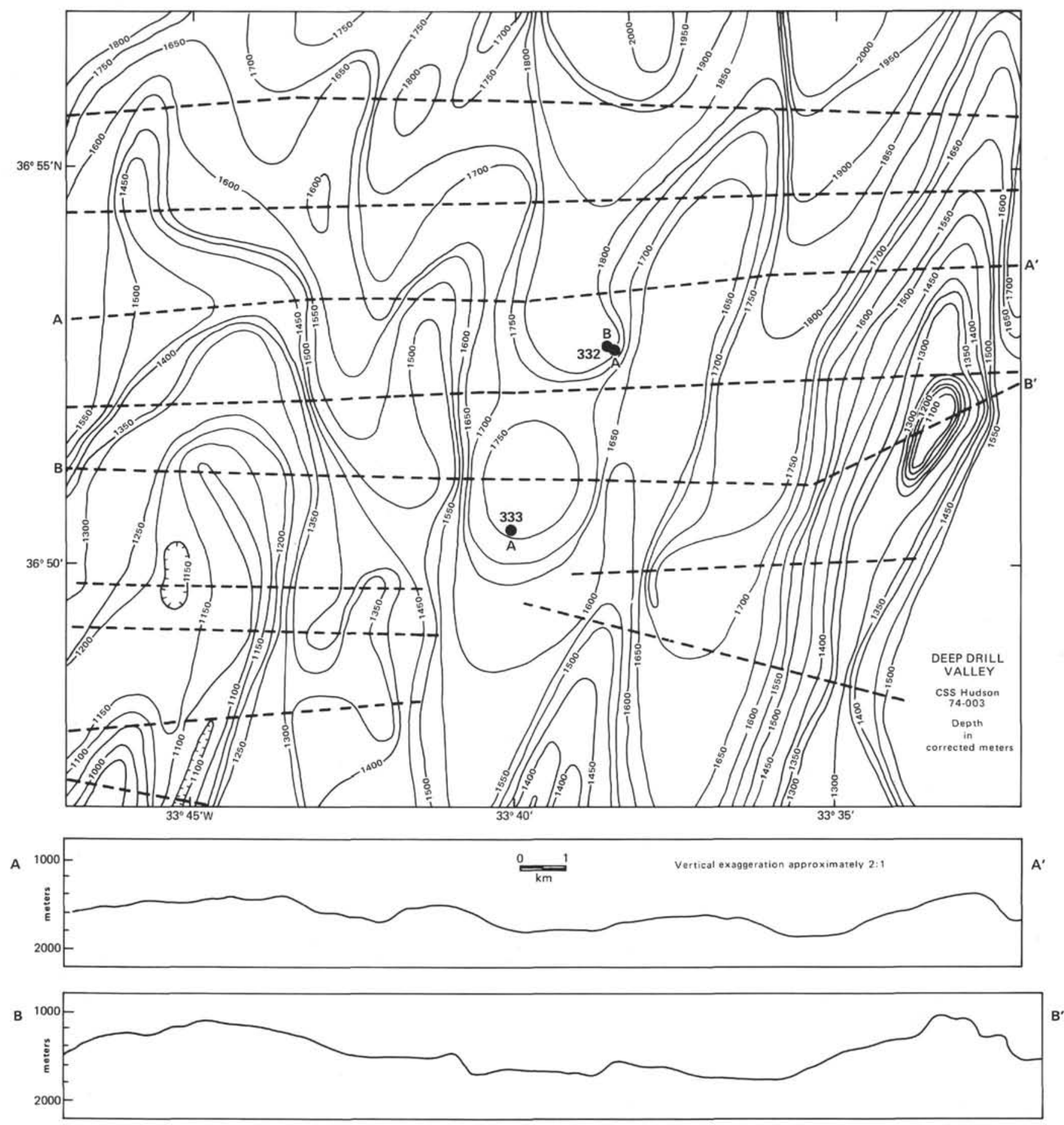

Figure 5. Bathymetric contour chart of Deep Drill Valley from CSS Hudson cruise 74-003 data. Contour interval 50 meters. Cross-section $A-A^{\prime}$, and $B-B$ ', show profiles along tracks $A-A$ ' and $B-B^{\prime}$ 'of the contour chart. 